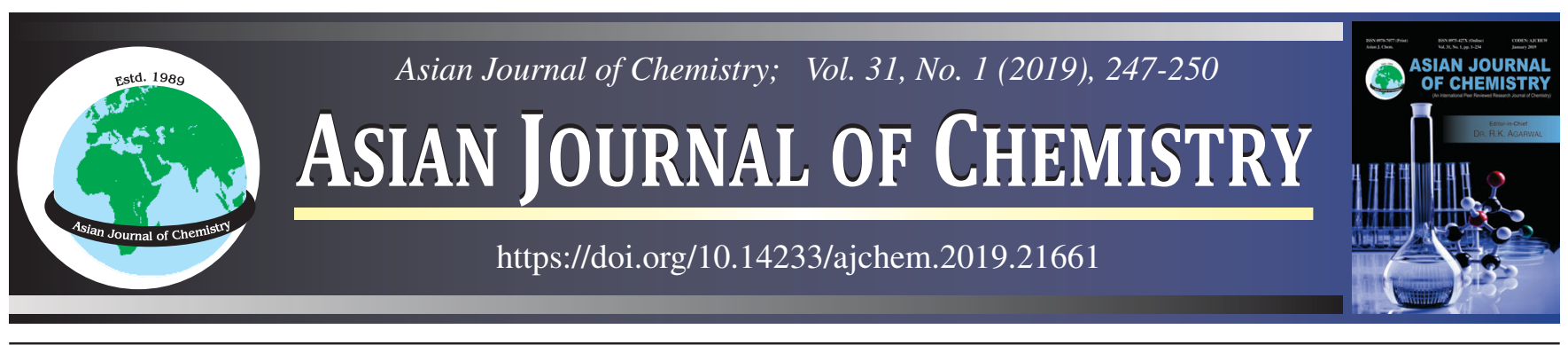

\title{
Synthesis of Multi-Walled Carbon Nanotubes from Iraqi Natural Gas/CO Mixture by Catalytic Flame Fragments Deposition Method
}

\author{
Firas H. AbdulrazzaK ${ }^{1}$, Ahmed M. Abbas² and Falah H. Hussein ${ }^{3,4, *}$ ()
}

${ }^{1}$ Department of Chemistry, College of Education for Pure Science, Diyala University, Diyala, Iraq

${ }^{2}$ Department of Chemistry, College of Education for Pure Science, Baghdad University, Baghdad, Iraq

${ }^{3}$ Department of Pharmaceutics, College of Pharmacy, Babylon University, Hilla, Iraq

${ }^{4}$ Department of Research and Studies, Al-Mustaqbal University College, Babylon, Iraq

*Corresponding author: E-mail: abohasan_hilla@yahoo.com

Received: 16 August 2018;

Accepted: 28 October 2018;

Published online: 30 November 2018;

AJC-19188

Multi-walled carbon nanotubes (MWNTs) were synthesized from Iraqis natural gas using flame under carbon monoxide atmosphere. The study focuses on abilities to synthesis and characterization of carbon nanotubes (CNTs) using simple, easy, low cost by natural material. The reactor has been designed for synthesis of carbon nanotubes CNTs from natural gas which acted as a source of carbon in addition to supplying thermal energy instead of electrical energy. Crystallographic and morphological of CNTs have been characterized using powder X-ray diffraction, Raman spectroscopy, transmission electron microscope and thermal gravimetric analysis. The analysis refers to synthesized MWNTs with purity $57.80 \%$ and outer diameter 6.6-17.9 nm, inner diameter 3.2-6.3 nm which equal to 3-9 of graphene layers while the length of tubes is 0.8 to $2 \mu \mathrm{m}$.

Keywords: Multi-walled carbon nanotubes, Natural gas, Reactor homemade, Carbon monoxide.

\section{INTRODUCTION}

The urgent need for nanotechnology in the 21th century has led to a growing demand for chemical compounds to achieve advanced technology. Maybe carbon nanotubes (CNTs) represent one of the common nanomaterials that used in huge applications such micro and nanoelectronics devices [1], drug delivery [2] energy and environmental applications [3]. The remarkable physio-chemical properties of CNTs have been foreword multiuse materials and still being tested for many applications. The abilities of CNTs to use in the different application not only for varying types such as SWNTs or MWNTs but a variant on orientations of carbon atoms [4] on graphene sheets. Many literatures $[5,6]$ reported the common routes of synthesis of CNTs such as arc-discharge, laser ablation and chemical vapour deposition.

Flame fragments deposition (FFD) method is one of many techniques used to synthesize carbon nanomaterials which depend on chemical materials as sources of carbon and source of energy for carbon deposition. Flame fragments deposition method [7] use hydrocarbon in gas phase such $\mathrm{CH}_{4}$ and $\mathrm{C}_{2} \mathrm{H}_{2}$ reacts with $\mathrm{O}_{2}$ to produce a gaseous mixture which includes $\mathrm{CO}_{2}, \mathrm{H}_{2} \mathrm{O}$,
$\mathrm{CO}, \mathrm{H}_{2}$ and many species of free radicals. The free radicals $[8,9]$ responsible for producing tubular structures on the upper side of the reactor. The influence of chemical energy [10] for decomposition carbon represented by limitation the carbon deposition with orientation endothermic reactions to build the tubular structure. This capacity is considered the most important characteristic which shows preference compared to the previous methods. Mostly, the flame methods use hydrocarbon gases with high purities which may cause limitation due to all of its use as a source of energy. Natural gases one of the components of crude oil mostly in oil countries which separated during the refining operations and disposed of by burning in refining towers, only a few ratios exploit. Natural gas is mainly mixture of methane, ethane, propane and butane, as well as $\mathrm{H}_{2} \mathrm{O}, \mathrm{CO}_{2}, \mathrm{~N}_{2}$ and some sulfur compounds. Awadallah et al. [11] synthesized MWNTs from natural gas as a carbon source using the catalytic chemical vapor deposition (CCVD) technique over Ni-Mo and Co-Mo supported on $\mathrm{Al}_{2} \mathrm{O}_{3}$ catalysts at $700{ }^{\circ} \mathrm{C}$ in a fixed horizontal reactor. According to the review the yield of carbon nanotubes was $55.01 \mathrm{wt} \%$ when use Ni-Mo as catalyst and $33.38 \mathrm{wt} \%$ for Co-Mo catalysts.

This is an open access journal, and articles are distributed under the terms of the Creative Commons Attribution-NonCommercial 4.0 International (CC BY-NC 4.0) License, which allows others to copy and redistribute the material in any medium or format, remix, transform, and build upon the material, as long as appropriate credit is given and the new creations are licensed under the identical terms. 
Bonadiman et al. [12] used natural gas to synthesize multiwalled carbon nanotubes and single-walled carbon nanotubes by catalytic chemical vapor deposition at $1000^{\circ} \mathrm{C}$. The process included using $\mathrm{MgO}$ as a catalyst support with $\mathrm{Fe}-\mathrm{Mo} / \mathrm{MgO}$ system which obtained by the impregnation to synthesis SWNTs and decomposition system was succeeded in synthesis MWNTs. Bang et al. [13] characterized CNTs and fullerene which had been collected in propane and natural gas flame emissions from domestic cooking stoves. Iraqis natural gas mostly consisted of propane and butane. In our present work, the simple and easy method of using the natural product as sources of energy and carbon which represent by flame fragments deposition method and Iraqi natural gas respectively were used to synthesize carbon nanotubes. Precipitation process was subjected in an atmosphere of carbon monoxide gas when forming from the decomposition of methanol alcohol inside the reactor. The product was characterized by X-ray diffraction, Raman spectroscopy, transmission electron microscopy and thermogravimetric analysis.

\section{EXPERIMENTAL}

Iraqis natural gas was supplied from local markets, which analysis in petroleum research and development center, on Iraqi. The analyses were performed in winter and Table- 1 shows the physical properties of natural gas and percentage volume of natural gas. The $\mathrm{H}_{2} \mathrm{O}_{2}$ was purchase from Barcelona, Spain in $30 \%$ percent weight. Methanol with purities $(99.93 \%)$ was supplied from Alfa, Aesar.

Precipitation unit: Fig. 1 shows the home-made reactor and the experimental setup for the synthesis of carbon nanotubes when achieved the flame. The reactor consists of a chamber with $8 \mathrm{~L}$ in capacity, with two laminar in the lower part with two sources of gases. In this case, part 5 refers to the surface of precipitation when decomposition was accrued which covered with aluminum foil. The system was supplied by thermal cable to control the temperature by thermal cable with $30 \mathrm{~cm}$ in length and ability to control the temperature until $800^{\circ} \mathrm{C}$ and accuracy $\pm 2^{\circ} \mathrm{C}$. The burner nozzle outlet diameter was $2.7 \mathrm{~cm}$, while the body inner tube diameter was $3 \mathrm{~cm}$ and height $8 \mathrm{~cm}$. The distances between the sources of combustion and the upper surface were $15 \mathrm{~cm}$. Two mass flow controllers with an accuracy of $\pm 2.5 \%$ (BROKER, DK800S-3) were used to control the mass flow rate of natural gas and air.

Synthesis of carbon nanotubes: The laminar of methanol start ignition with an excess amount of oxygen for $10 \mathrm{~min}$. The role of methanol was reducing of oxygen in the chamber with produce excess amount of $\mathrm{CO}$ as the atmosphere of precipitation with a minimum value of soot and keep the temperature in the lower section of chamber at $150{ }^{\circ} \mathrm{C}$. After that the laminar of natural gas start to ignition for $20 \mathrm{~min}$ with maintaining the methanol laminar working with fixed flaw rate for $\mathrm{O}_{2} /$ natural

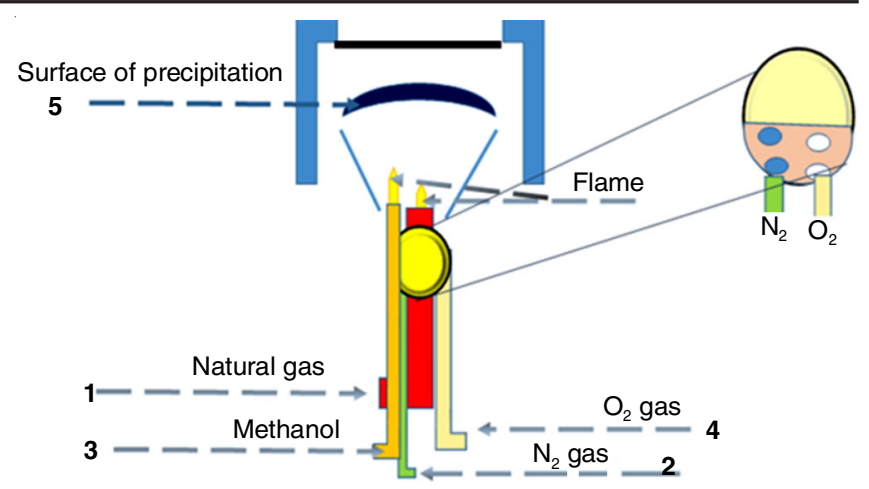

Fig. 1. Schematic diagram of homemade reactor and experimental setup for synthesis carbon nanotubes

(3/1) gas $600 \mathrm{~cm}^{3}$. After that stopped flow $\mathrm{O}_{2} /$ natural gas and methanol with the cool chamber to room temperature by the flow of nitrogen gas with flow rate $500 \mathrm{~cm}^{3} / \mathrm{min}$.

Purification process: As-prepared CNTs were purified as we reported in our previous work [14]. Briefly, $125 \mathrm{mg}$ of as-prepared sample was desperation with an ultrasonic water bath in $150 \mathrm{~mL}$ ethanol alcohol for $10 \mathrm{~min}$. The complementary of first step includes using separation funnel, to re-distribute the components which form the aggregate particles that removed from the solution. After filtration and drying at $70^{\circ} \mathrm{C}$, the sample was treated with $150 \mathrm{~mL}$ of $\mathrm{H}_{2} \mathrm{O}_{2}$ at $15^{\circ} \mathrm{C}$ for $12 \mathrm{~h}$ with stirring by a magnetic stirrer. The solution allowed to reach for room temperature, then heating gradually to $80^{\circ} \mathrm{C}$ to complete dissociation most of $\mathrm{H}_{2} \mathrm{O}_{2}$. Finally, the sample was washed with distilled water and dried at $100{ }^{\circ} \mathrm{C}$ for $12 \mathrm{~h}$.

Characterization: $\mathrm{X}$-ray diffraction (XRD) patterns were done on a (RigakuRotalflex) (RU-200B) X-ray diffractometer using $\mathrm{CuK} \alpha$ radiation $(\lambda=0.15405 \mathrm{~nm})$ with a $\mathrm{Ni}$ filter. The tube current was $100 \mathrm{~mA}$ with a tube voltage of $40 \mathrm{kV}$. The $2 \theta$ angular regions between 10 and $85^{\circ}$ were explored at a scan rate of $5 \%$ min with resolution at $0.02^{\circ}$. Raman analysis was performed from 100-3400 $\mathrm{cm}^{-1}$ by Sentara infinity 1 Bruker with using laser light at $530 \mathrm{~nm}$, for 5 lops per $2 \mathrm{sec}$ and resolution equal to 3-5 cm.Transmission electron microscopy was done by (Philips CM30 microscope operating at $300 \mathrm{kV}$ ) which equipped with a Gatan SS CCD camera and a Digital Micrograph software for the acquisition of electron diffraction patterns. TGA measurements were carried out in $\mathrm{Al}_{2} \mathrm{O}_{3}$ crucibles in a nitrogen atmosphere at a heating rate of $10^{\circ} \mathrm{C} / \mathrm{min}$ using a TG 209 F3 Tarsus ${ }^{\circledR}$ instrument (Netzsch, Germany).

\section{RESULTS AND DISCUSSION}

X-ray diffraction analysis: Fig. 2 shows two peaks at $25.06^{\circ}$ and $43.14^{\circ}$ which commonly seen with carbon nanotubes [14]. Mostly, the two peaks can be attributed to the diffraction from $\mathrm{C}(100)$ and $\mathrm{C}(002)$ planes of the carbon nanotubes, respectively.

TABLE-1

PHYSICAL PROPERTIES AND VOLUMETRIC RATIOS OF IRAQI NATURAL GAS CONTENTS

\begin{tabular}{lc|cc}
\hline \multicolumn{1}{c|}{ Physical properties } & Values & Component & Volumetric ratio (\% V max) \\
\hline Vapour pressure at $37.8{ }^{\circ} \mathrm{C}$ & $10 \mathrm{~kg} / \mathrm{cm}^{2}$ & Ethane & 0.6 \\
Heat vapourization $95 \%$ & $2.2^{\circ} \mathrm{C}$ & Propane & $60-70$ \\
Density at $15{ }^{\circ} \mathrm{C}$ & $0.534-0.551 \mathrm{~g} / \mathrm{cm}^{3}$ & Butane & $30-40$ \\
Residual of vapourized $100 \mathrm{~mL}$ & $0.05 \mathrm{~mL}$ & $<\mathrm{C} 5$ & 2.0 \\
& & Sulphite content & $150 \mathrm{ppm}$ \\
\hline
\end{tabular}






Fig. 2. X-ray diffraction pattern of synthesized multi-walled carbon nanotube

Raman analysis: Raman spectrum (Fig. 3) showed the main peak which is the $\mathrm{D}$ and $\mathrm{G}$ bands at 1369 and $1595 \mathrm{~cm}^{-1}$, respectively [15]. The $\mathrm{D}$ band is induced to disordered carbon atoms or may relate to $s p^{3}$ hybridized of carbon nanotubes. The $\mathrm{G}$ band is due to the $s p^{2}$ hybridized derived from splitting of $\mathrm{E}_{2 \mathrm{~g}}$ stretching mode in sheets of graphite. The distinguishable feature of CNTs was G+D band at $2964 \mathrm{~cm}^{-1}$ which appear as weak peak [16,17]. The increased intensity of $\mathrm{D}$ band as compared to $\mathrm{G}$ band mostly refers to the functional groups which produce during production and purification process with hydrogen peroxide [18]. The law ratios (ID/IG $=0.92$ ); may be related to reducing the intensity of the $\mathrm{G}$ band due to the presence of high defects on the walls of tubes. The $\mathrm{G}$ and $\mathrm{D}$ band observed as wide with semi-equals high due to an amorphous phase and high degree of disorder in the structure of $s p^{2}$ hybridized to graphite structure at low-temperature growth [19].

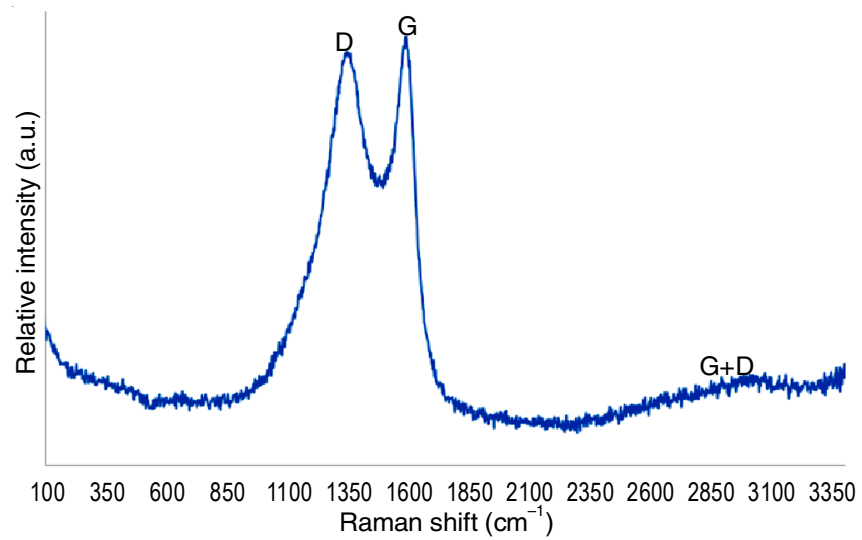

Fig. 3. Raman spectra of synthesized MWNTs by flame fragments deposition method

TEM analysis: TEM shows the images of as-prepared tubular strictures with many balls which referred to unconverted carbon (Fig. 4). The image shows filaments of carbon nanotubes with diameter arrange between 6.6 to $17.9 \mathrm{~nm}$ and the inner diameter of nanotubes between 3.2-6.3 $\mathrm{nm}$ with a thickness of wall reach to $11.6 \mathrm{~nm}$. From the inner and external diameter, it can be concluded that the number of graphene layers arranged from 3-9 layers which are mostly MWNTs [20].

Thermal analysis: The thermogram (Fig 5) shows three regions, the first region between $100-425^{\circ} \mathrm{C}$ when $2.49 \%$ loss mass due to the evaporation of adsorbed water [21] and decom-

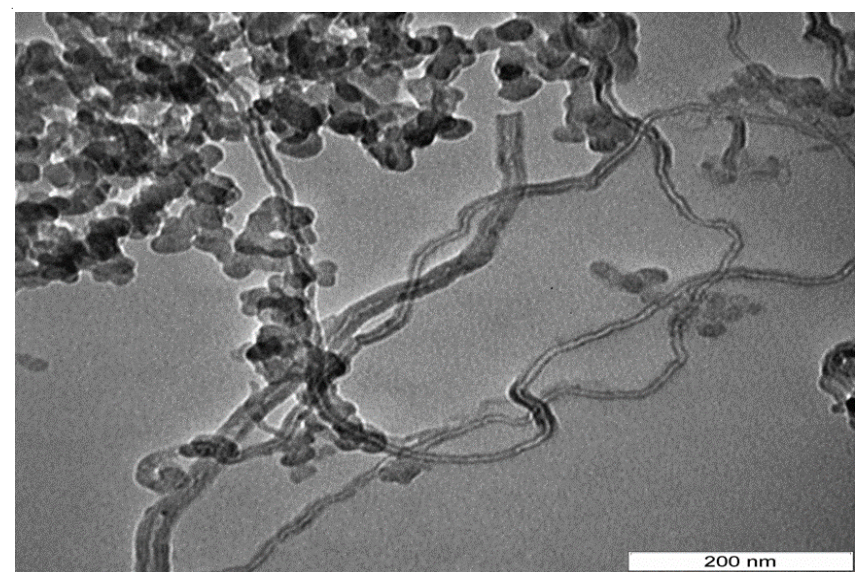

Fig. 4. TEM image of synthesized MWNTs by flame fragments deposition method

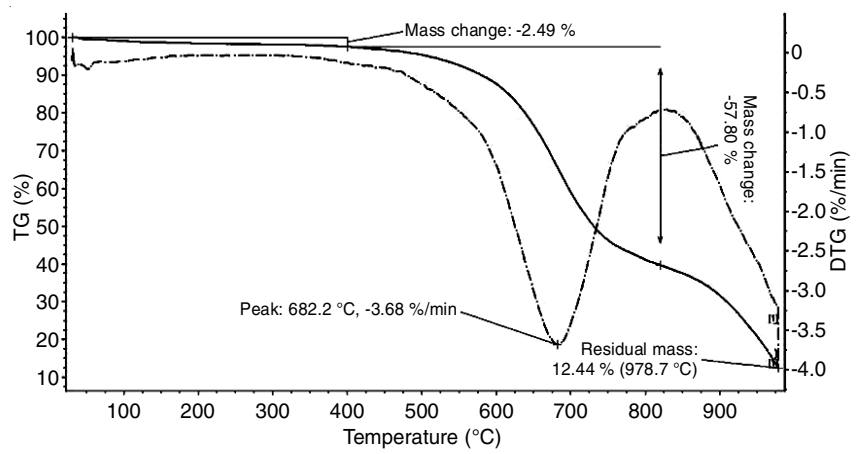

Fig. 5. TGA of synthesized carbon nanotubes after purification

position unconverted carbon [22]. The second part of 425-682 ${ }^{\circ} \mathrm{C}$ witnessed a loss $57.80 \%$ of mass that can be related to decomposition of synthesized CNTs [22,23] with a clear exothermic peak for decomposition of synthesized MWNTs [24]. The residual materials showed $12.44 \%$ due to the remaining support of aluminum compound used in preparation method.

The important of this work can be related to synthesis of MWNTs at low temperature, high production and low cost without catalyst which make the process of purification easier. The role of CO not only as sources to consume the oxygen in the chamber of reaction but as an initiator of carbon to produce tubular structures. The $\mathrm{CO}$ atmosphere behaves as donor and catalyzer when the reversible reaction of $\mathrm{CO}$ to produce $\mathrm{CO}_{2}$ and carbon [25]. Natural gas as mixture of aliphatic and aromatic hydrocarbons can produce carbon with high concentration $[26,27]$ which catalyzed to precipitate over carbon free radical produced with the decomposition of methanol. Therefore, the precipitation accrued due to inner catalyzer from $\mathrm{CO}$ whereas paves the way for the process of carbon deposition without using a transition metal catalyst.

\section{Conclusion}

Multi-wall carbon nanotubes successfully synthesized by flame method shows a high efficiency to make precipitation in easy and safety manner without any complication. Flame fragments deposition synthesis has been utilized to produce CNTs from Iraqis natural gas in $\mathrm{CO}$ atmosphere at aluminum foil as surfaces of precipitation. Thermogravimetric analysis and TEM images show that the CNT samples contained 57.80 $\%$ of MWNTs. The method can be modified to be ideal for 
synthesis different types of carbon nanotubes in additions to abilities to make its ideals towards high quantities.

\section{CONFLICT OF INTEREST}

The authors declare that there is no conflict of interests regarding the publication of this article.

\section{REFERENCES}

1. Y. Che, H. Chen, H. Gui, J. Liu, B. Liu and C. Zhou, Semicond. Sci. Technol., 29, 073001 (2014);

https://doi.org/10.1088/0268-1242/29/7/073001.

2. A. Bianco, K. Kostarelos and M. Prato, Curr. Opin. Chem. Biol., 9, 674 (2005); https://doi.org/10.1016/j.cbpa.2005.10.005

3. Y.T. Ong, A.L. Ahmad, S.H.S. Zein and S.H. Tan, Braz. J. Chem. Eng., 27, 227 (2010);

https://doi.org/10.1590/S0104-66322010000200002.

4. K. Tanaka and S. Iijima, Carbon Nanotubes and Graphene, Elsevier, edn 2 (2014).

5. V. Popov, Mater. Sci. Eng. Rep., 43, 61 (2004); https://doi.org/10.1016/j.mser.2003.10.001.

6. K. Xia, H. Zhan and Y. Gu, Procedia IUTAM, 21, 94 (2017); https://doi.org/10.1016/j.piutam.2017.03.042.

7. B. Hall, C. Zhuo, Y.A. Levendis and H. Richter, Carbon, 49, 3412 (2011); https://doi.org/10.1016/j.carbon.2011.04.036.

8. R.L. Vander Wal, T.M. Ticich and V.E. Curtis, Carbon, 39, 2277 (2001); https://doi.org/10.1016/S0008-6223(01)00047-1.

9. P. Reilly and W. Whitten, Carbon, 44, 1653 (2006); https://doi.org/10.1016/j.carbon.2006.01.018.

10. J.B. Howard, J.T. McKinnon, Y. Makarovsky, A.L. Lafleur and M.E. Johnson, Nature, 352, 139 (1991); https://doi.org/10.1038/352139a0.

11. A.E. Awadallah, S.M. Abdel-Hamid, D.S. El-Desouki, A.A. AboulEnein and A.K. Aboul-Gheit, Egypt. J. Petr., 21, 101 (2012); https://doi.org/10.1016/j.ejpe.2012.11.005.

12. R. Bonadiman, M.D. Lima, M.J. De Andrade and C.P. Bergmann, J. Mater. Sci., 41, 7288 (2006); https://doi.org/10.1007/s10853-006-0938-2.
13. J.J. Bang, P.A. Guerrero, D.A. Lopez, L.E. Murr and E.V. Esquivel, J. Nano. Nanotech., 4, 716 (2004); https://doi.org/10.1166/jnn.2004.095.

14. F.H. Abdulrazzak, S.K. Esmail, H.A. Dawod, A.M. Abbas and M.K.K. Almaliki, Int. J. Theo. Appl. Sci., 8, 37 (2016).

15. S. Costa, E. Palen, M. Kruszynsky, A. Bachimatiuk and R. Kalenczuk, Mater. Sci. Poland, 26, 433 (2008).

16. A. Ferrari and J. Robertson, Phys. Rev. B, 61, 14095 (2000); https://doi.org/10.1103/PhysRevB.61.14095.

17. S. Abbasi, S.M. Zebarjad and S.H. Noie-Baghban, Engineering, 5, 207 (2013); https://doi.org/10.4236/eng.2013.52030.

18. X. Zeng, S. Yu, L. Ye, M. Li, Z. Pan, R. Sun and J. Xu, J. Mater. Chem. C, 3, 187 (2015); https://doi.org/10.1039/C4TC01051E.

19. M. Nazhipkyzy, B.T. Lesbaev, N.G. Prikhodko, Z.A. Mansurov and R.R. Nemkaeva, Univ. J. Appl. Sci., 3, 17 (2015).

20. A. Szabó, C. Perri, A. Csató, G. Giordano, D. Vuono and J.B. Nagy, Materials, 3, 3092 (2010); https://doi.org/10.3390/ma3053092.

21. V. Datsyuk, M. Kalyva, K. Papagelis, J. Parthenios, D. Tasis, A. Siokou, I. Kallitsis and C. Galiotis, Carbon, 46, 833 (2008); https://doi.org/10.1016/j.carbon.2008.02.012.

22. E. Ordoñez-Casanova, M. Román-Aguirre, A. Aguilar-Elguezabal and F. Espinosa-Magaña, Mater, 6, 2534 (2013); https://doi.org/10.3390/ma6062534.

23. A.B. Suriani, A.A. Azira, S.F. Nik, R.M. Nor and M. Rusop, Mater. Lett., 63, 2704 (2009); https://doi.org/10.1016/j.matlet.2009.09.048.

24. P. Jagdale, M. Sharon, G. Kalita, N.M.N. Maldar and M. Sharon, $A d v$. Mater. Phys. Chem., 2, 1 (2012); https://doi.org/10.4236/ampc.2012.21001.

25. F.W. Geurts and J.A. Sacco Jr., Carbon, 30, 415 (1992); https://doi.org/10.1016/0008-6223(92)90039-Y.

26. H. Endo, K. Kuwana, K. Saito, D. Qian, R. Andrews and E.A. Grulke, Chem. Phys. Lett., 387, 307 (2004); https://doi.org/10.1016/j.cplett.2004.01.124.

27. A.M. Jassm, F.H. Hussein, F.H. Abdulrazzak, A.F. Alkaim and B.A. Joda, Asian J. Chem., 29, 2804 (2017); https://doi.org/10.14233/ajchem.2017.20994. 